\title{
Dislocation formation in silicon implanted at different temperatures
}

\author{
J. R. Liefting ${ }^{\mathrm{a}, \mathrm{b}}$, J. S. Custer ${ }^{\mathrm{b}}$, R. J. Schreutelkamp ${ }^{\mathrm{c}}$ and F. W. Saris ${ }^{\mathrm{b}}$ \\ ${ }^{a}$ University of Twente, MESA Research Institute, Postbox 217, 7500AE Eschede (Netherlands) \\ ${ }^{b}$ Present address: FOM Institute for Atomic and Molecular Physics, Kruislaan 407, 1098 SJ Amsterdam (Netherlands) \\ ${ }^{\mathrm{c}} I M E C$ vzw, Kapeldreef 75, B-3001 Heverlee (Belgium)
}

(Received June 10, 1992)

\begin{abstract}
The formation of pre-amorphization damage, i.e. dislocations formed by the agglomeration of silicon interstitials, requires a minimum amount of implant damage. The amount of damage can be altered by changing the implant temperature or current density, which can influence dislocation formation. We studied this using cross-sectional transmission electron microscopy for boron and indium implants at kiloelectronvolt and megaelectronvolt energies respectively. Dislocation formation for boron implants, where only simple cascade densities are generated, does not depend on implant temperature or current density. For $1 \mathrm{MeV}$ indium implants, where the implant damage consists mainly of amorphous zones, an increase in critical dose for dislocation formation by a factor of approximately 3 is observed if the implant temperature is raised. This is attributed to the interaction of point defects with the amorphous zones during the elevated temperature implant. Implants of $150 \mathrm{keV}$ indium at room temperature result in complete amorphization before the critical amount of crystal damage is reached. Here, end-of-range loops (EOR-loops) form after annealing. Increasing the implant temperature suppresses amorphization, and pre-amorphization damage is observed if a critical amount of crystal damage has been generated. EOR-loop formation results from the agglomeration of silicon interstitials from the amorphous-crystalline transition region. If the number of interstitials in this region is lowered by carrying out the implant at low temperature, EOR-loop formation can be suppressed. This is shown by comparing amorphizing germanium implants done at room and liquid nitrogen temperatures.
\end{abstract}

\section{Introduction}

Ion implantation is commonly used for introducing dopants into silicon. The ions enter the substrate and come to rest in typically $10^{-13} \mathrm{~s}$ by nuclear and electronic stopping mechanisms [1]. The nuclear interactions give rise to displacements of silicon host atoms. For low mass implants, the displacement cascade densities are low and generally only simple vacancyand interstitial-related defects are created. These point defects are not stable at room temperature (RT), thus they either recombine or form larger point defect clusters $[2,3]$. Such clusters also form for high mass implants, but in addition amorphous zones (a-zones) are created by the dense cascades [4]. The configuration of defect complexes and a-zones remaining after the implant is called the primary damage.

Annealing of primary damage below the amorphization threshold results in the formation of category I dis- locations, also known as pre-amorphization damage, if a critical amount of primary damage has been exceeded [5]. This criterion for dislocation formation has been demonstrated for RT implants of ions ranging from low mass $\left({ }^{11} \mathrm{~B}\right)$ to high mass $\left({ }^{115} \mathrm{In},{ }^{121} \mathrm{Sb}\right)$. The critical amount of primary damage corresponds to a number of displaced silicon atoms of approximately $10^{16} \mathrm{~cm}^{-2}$ for boron and approximately $10^{17} \mathrm{~cm}^{-2}$ for indium implants, according to Rutherford backscattering spectrometry (RBS) and channeling analysis [5]. This difference in number was attributed to the difference in primary damage morphology for the boron (simple point defect complexes) and indium (in addition a-zones) implants. The displaced silicon atoms inside the a-zones do not contribute to dislocation formation because the a-zones recrystallize upon annealing.

Changing the amount of primary damage could result in a change in dislocation formation. The amount 
and type of primary damage is influenced by several parameters. (1) Increasing the mass of the implanted ion results in a change from only point defect clusters for low mass ions to a damage morphology mainly consisting of a-zones for high mass ions [5, 6]. (2) Implanting at higher energy distributes the primary damage over a larger depth. For high mass implants, the critical amount of primary damage is then obtained before the amorphization threshold is reached [5]. (3) Performing the implant at an elevated temperature enhances annealing during the implant. For $1 \mathrm{MeV}$ silicon implants, an increase in implant temperature of $30{ }^{\circ} \mathrm{C}$ can reduce the amount of primary damage by $90 \%$ [7]. High mass implants, which normally result in amorphous surface layers for RT implants, only generate crystalline damage if the implant is performed at higher temperatures [8]. (4) The influence of the implant dose on the amount of primary damage is strongly dependent on the type of primary damage formed. A linear dependence on implant dose is observed for high mass implants done at RT [8]. Implants of low mass ions or elevated temperature implants result in a damage build-up that is strongly non-linear with dose [6-8]. (5) Different ion fluxes give rise to different defect production rates in silicon [7]. For a high defect production rate, it is easy for the point defects to interact and form larger complexes. For a low defect production rate, the point defects anneal before they can interact and form more stable defect complexes. Therefore, the highest amount of primary damage results from implants carried out with the highest flux. From the above, it is concluded that there are several ways to lower the amount of primary damage. Increasing the implant temperature or decreasing the ion flux may therefore help reduce dislocation formation.

For kiloelectronvolt high mass implants carried out at RT, the amorphization threshold is attained before the critical amount of primary damage is reached. However, amorphization is avoided if the implant is performed at a sufficiently high substrate temperature $[8,9]$. The primary damage then consists only of crystal damage. Again, a critical amount of crystal damage should be required to form dislocations during thermal treatment.

Annealing an amorphous layer results in the formation of end of range loops (EOR-loops) near the original amorphous-crystalline $(\mathrm{a}-\mathrm{c})$ transition region $[6,10]$. The extrinsic loops result from the agglomeration of silicon interstitials which are positioned in the a-c transition region [11]. For a certain implant dose, the amount of crystal damage in this region can be lowered if the implant is done at a lower temperature $[12,13]$. If the amount of damage is lower than a critical number, EOR-loop formation might be avoided [11]. Servidori and Vecchi indeed showed that for
$2 \times 10^{15} \mathrm{~cm}^{-2} 100 \mathrm{keV}$ phosphorus implants, dislocations were observed for RT implants, in contrast to implants performed at liquid nitrogen temperature $\left[\mathbf{L N}_{2}\right)[14]$.

In the first part of this paper, we report on dislocation formation for low (boron) and high (indium) mass implanted silicon. The primary damage for boron implants was altered by changing the implant temperature and the implant flux. Only smaller point defect clusters are formed for these boron implants, hence only some annihilation and coarsening of the point defect clusters is expected. Cross-sectional transmission electron microscopy (XTEM) analysis will show the influence of this change in primary damage on dislocation formation. For comparison, the primary damage for indium implants was also changed by performing the implants at different temperatures. Here, a larger influence on dislocation formation is expected, since a-zones are not stable at higher temperatures and could influence the point defect configuration. By comparing the results for the boron and indium implants, the influence of a-zones on dislocation formation can be determined.

The second part of this paper discusses the dislocation formation for low energy indium implants. EORloops result from annealing the $\mathrm{RT}$ implants. Amorphization is avoided when the implant is performed at $300{ }^{\circ} \mathrm{C}$ and pre-amorphization damage should be observed when the amount of crystal damage exceeds the critical amount.

Finally, in the third part, it is shown that EOR-loop formation can be avoided. This is demonstrated for 75 keV germanium implants.

\section{Experimental details}

Implants of ${ }^{11} \mathrm{~B},{ }^{73} \mathrm{Ge}$, and ${ }^{115} \mathrm{In}$ with energies between $75 \mathrm{keV}$ and $1 \mathrm{MeV}$ were done in $5-15 \Omega \mathrm{cm}$, p-type float zone (100) silicon in a random direction. A current density lower than $20 \mathrm{nA} \mathrm{cm} \mathrm{cm}^{-2}$ was used, unless otherwise specified. The samples (approximately $15 \times 15 \mathrm{~mm}^{2}$ ) were mounted on a molybdenum or copper block cooled by liquid nitrogen or heated to temperatures up to $500{ }^{\circ} \mathrm{C}$ by a tungsten filament. The temperature was monitored with a $\mathrm{Pt} 100$ resistor mounted in the molybdenum block or with a thermocouple mounted on the copper block. The number of displaced silicon atoms in the as-implanted samples was determined using $2 \mathrm{MeV} \mathrm{He}^{+} \mathrm{RBS}$ in the channeling geometry [15]. The implanted samples were annealed in a vacuum furnace (base pressure approximately $10^{-7}$ Torr). Cross-sectional and plan-view TEM were done in the bright-field mode using a Siemens Elmiskop 101 microscope. 


\section{Pre-amorphization damage for low (boron) and high (indium) mass implants}

\subsection{Boron implants}

Dislocation formation was investigated for $200 \mathrm{keV}$ and $1 \mathrm{MeV}{ }^{11} \mathrm{~B}$ implants. Figure 1 shows XTEM images after $15 \mathrm{~min}, 900^{\circ} \mathrm{C}$ anneals of samples implanted with $200 \mathrm{keV}$ boron for different doses and implant temperatures. No dislocations are observed for a room temperature (RT) implant of $0.7 \times 10^{14} \mathrm{~B}$ $\mathrm{cm}^{-2}$, but they are seen for $1.0 \times 10^{14} \mathrm{~B} \mathrm{~cm}^{-2}$. Hence, the latter dose is the threshold dose which generates the critical amount of damage needed for dislocation formation for RT implants. If raising the implant temperature helped suppress dislocation formation, the threshold dose should increase for higher implant temperatures. However, dislocations are still observed for $1.0 \times 10^{14} \mathrm{~B} \mathrm{~cm}^{-2}$ implants at either $200-400{ }^{\circ} \mathrm{C}$. The concentration of dislocations increases for the $400{ }^{\circ} \mathrm{C}$ implant if the dose is raised to $2.0 \times 10^{14} \mathrm{~B}$ $\mathrm{cm}^{-2}$. Thus, the dose required for dislocation formation for $200 \mathrm{keV}$ boron implants is not influenced if the implant temperature is raised from 25 to $400{ }^{\circ} \mathrm{C}$.

Implants of $5 \times 10^{14} \mathrm{~cm}^{-2} 1 \mathrm{MeV}$ boron were performed at temperatures ranging from 25 to $400^{\circ} \mathrm{C}$. The beam current density on the target was $15 \mathrm{nA}$ $\mathrm{cm}^{-2}$. This does generates around eight times the critical amount of damage required for dislocation formation for $1 \mathrm{MeV}$ boron implants [5]. RBS channeling spectra of the samples are shown in Fig. 2. Also shown is the spectrun of unimplanted silicon. The dechanneling is highest for the RT implant and decreases for increasing temperature. Therefore, the RBS-measured primary damage is reduced if the implant is done at an elevated temperature.

XTEM images of annealed samples implanted at 25, 200 , and $400{ }^{\circ} \mathrm{C}$ are presented in Fig. 3. The anneal was done at $900^{\circ} \mathrm{C}$ for $15 \mathrm{~min}$. A band of elongated dislocation loops with lengths up to $1.0 \mu \mathrm{m}$ positioned at a depth of around $1.6 \mu \mathrm{m}$ is observed for the RT implant. The micrographs for the 200 and $400{ }^{\circ} \mathrm{C}$ implants do not show any reduction in dislocation formation. Again, raising the implant temperature does not influence the dislocation formation for boron implants, even though the primary damage levels measured by RBS were different.

Implants of $5 \times 10^{14} \mathrm{~cm}^{-2} 1 \mathrm{MeV}$ boron at $400{ }^{\circ} \mathrm{C}$ were also performed at higher current densities of 150 and $1500 \mathrm{nA} \mathrm{cm}^{-2}$. RBS channeling measurements of these samples are presented in Fig. 4. The sample implanted at the lowest current density results in the lowest dechanneling yield. The highest yield, and thus the highest amount of primary damage, is found for the sample implanted at a current density of $1500 \mathrm{nA}$ $\mathrm{cm}^{-2}$.
XTEM images of these samples (Fig. 5) all show a band of elongated dislocations positioned at a depth of about $1.6 \mu \mathrm{m}$ with no observable difference in dislocation size or density. Thus, changing the primary damage by changing the current density of the boron implant does not seem to influence dislocation formation.

The only number which is important for dislocation formation for the boron implants is the total number of silicon atoms displaced during the implant. The structure of defect complexes formed during implantation, which was altered by changing either the implant temperature or the flux, is apparently not so critical.

\subsection{Indium implants}

Implants of high mass ions at RT result in high cascade densities which lead to the formation of amorphous zones (a-zones). By performing implants of indium at elevated temperatures, the a-zones will decrease in size or may not form at all. This will also influence the diffusion and population of point defects, and a large change in primary damage is expected. By comparing results for both boron and indium implants, the influence of a-zones on the point defect population, and therefore on dislocation formation, can be investigated.

Figure 6 shows XTEM images after annealing of samples implanted with $1 \mathrm{MeV}{ }^{115}$ In for different doses and implant temperatures. For implants at $-85^{\circ} \mathrm{C}$, no dislocations are observed for a dose of $0.5 \times 10^{13} \mathrm{In}$ $\mathrm{cm}^{-2}$ after $900{ }^{\circ} \mathrm{C}, 15 \mathrm{~min}$ annealing. Only one dislocation was found in the XTEM sample for a dose of $1.0 \times 10^{13} \mathrm{In} \mathrm{cm}^{-2}$, while a band of dislocation loops at a depth of $0.4 \mu \mathrm{m}$ is observed for a dose of $1.5 \times 10^{13}$ In $\mathrm{cm}^{-2}$. In contrast, dislocations for RT implants only begin to appear between 1.5 and $2.0 \times 10^{13} \mathrm{In} \mathrm{cm}^{-2}$, in agreement with previous results [5]. The concentration of loops further increases for $3.0 \times 10^{13} \mathrm{In} \mathrm{cm}^{-2}$. For implants at $400{ }^{\circ} \mathrm{C}$, dislocations are not observed until a dose of $3.0 \times 10^{13} \mathrm{In} \mathrm{cm}^{-2}$.

The results for temperatures ranging from $-85^{\circ} \mathrm{C}$ to $500{ }^{\circ} \mathrm{C}$ are summarized in Fig. 7. The indium threshold dose for dislocation formation is represented by the drawn line and increases by a factor of approximately 3 across this temperature range, saturating at around $400{ }^{\circ} \mathrm{C}$.

Figure 8 shows RBS channeling spectra for indium doses closest to the critical dose at several implant temperatures. The primary damage in the silicon is highest for an implant at $-85^{\circ} \mathrm{C}$ and consists of $1.9 \times 10^{17}$ $\mathrm{cm}^{-2}$ displaced silicon atoms. This number is calculated by subtracting the dechanneling contribution from the total yield [15]. The number of displaced silicon atoms estimated from the RBS spectra decreases with increasing implant temperature, see Table 1 . The 

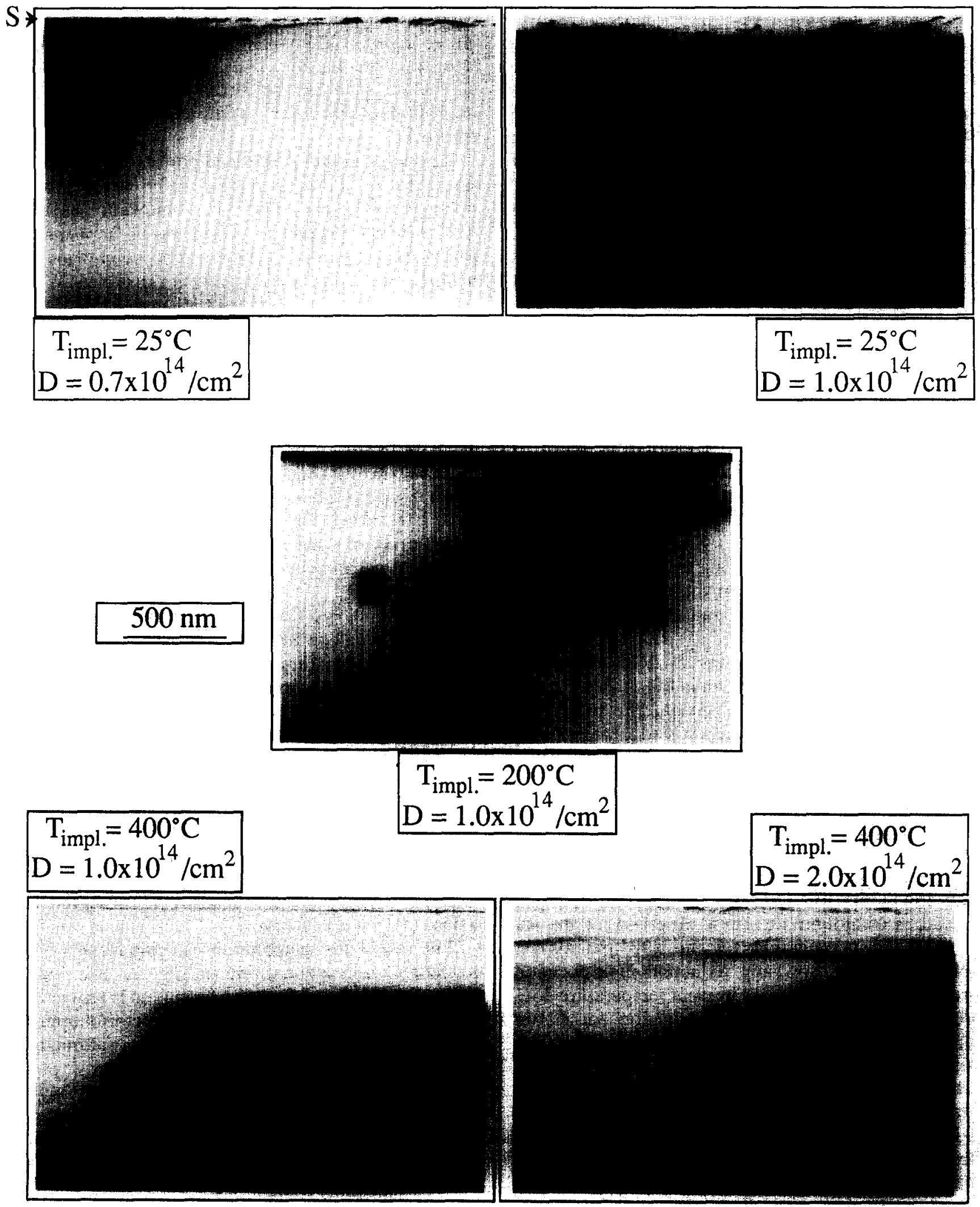

Fig. 1. XTEM images of samples implanted with $200 \mathrm{keV}{ }^{11} \mathrm{~B}$ and annealed at $900^{\circ} \mathrm{C}$ for 15 min. Implant doses and temperatures are denoted in the figure. 
critical number needed for dislocation formation was determined by combining the RBS and XTEM results. For RT implants, this number is $1.9 \times 10^{17} \mathrm{~cm}^{-2}$, similar to previous results [5]. The critical number

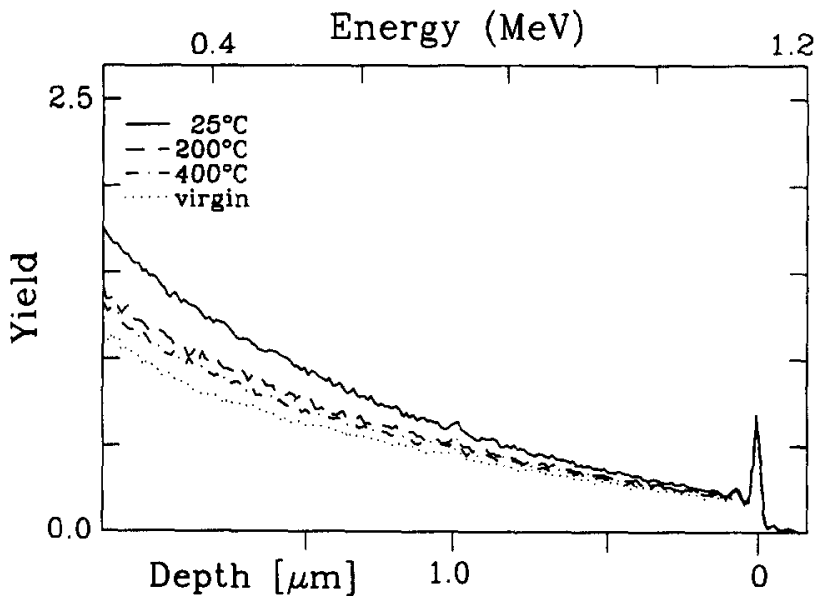

Fig. 2. RBS channeling spectra of silicon implanted with $5 \times 10^{14}$ $\mathrm{cm}^{-2} 1 \mathrm{MeV}$ boron at 25,200 , or $400^{\circ} \mathrm{C}$. A spectrum of unimplanted silicon is shown for comparison. decreases by a factor of about 40 with increasing substrate temperature below $10^{16} \mathrm{~cm}^{-2}$ for implants done at $500{ }^{\circ} \mathrm{C}$. This number is close to the critical number found for boron implants, in which case no a-zones are created [5].

At implant temperatures of about $400{ }^{\circ} \mathrm{C}$, isolated a-zones anneal out $[9,16]$. Such annealing of amorphous silicon may influence the point defect population, and thereby dislocation formation. Annealing an indium implanted sample at $400{ }^{\circ} \mathrm{C}$ prior to the high temperature treatment may also influence dislocation formation. Figure 9 shows RBS channeling spectra for $3 \times 10^{13} \mathrm{~cm}^{-2} 1 \mathrm{MeV}$ indium implants at 25 and $400{ }^{\circ} \mathrm{C}$. Part of the RT implanted sample was subsequently annealed at $400{ }^{\circ} \mathrm{C}$ for $3 \mathrm{~h}$, much longer than the $0.5 \mathrm{~h}$ needed to perform the implants. The highest dechanneling, found for the sample implanted at RT, peaks at a depth of $0.4 \mu \mathrm{m}$ and corresponds to approximately $3.6 \times 10^{17} \mathrm{~cm}^{-2}$ displaced silicon atoms (Table 1). Annealing this sample at $400{ }^{\circ} \mathrm{C}$ for $3 \mathrm{~h}$ substantially reduces the measured number of displaced silicon atoms to $4.7 \times 10^{16} \mathrm{~cm}^{-2}$. However, an even

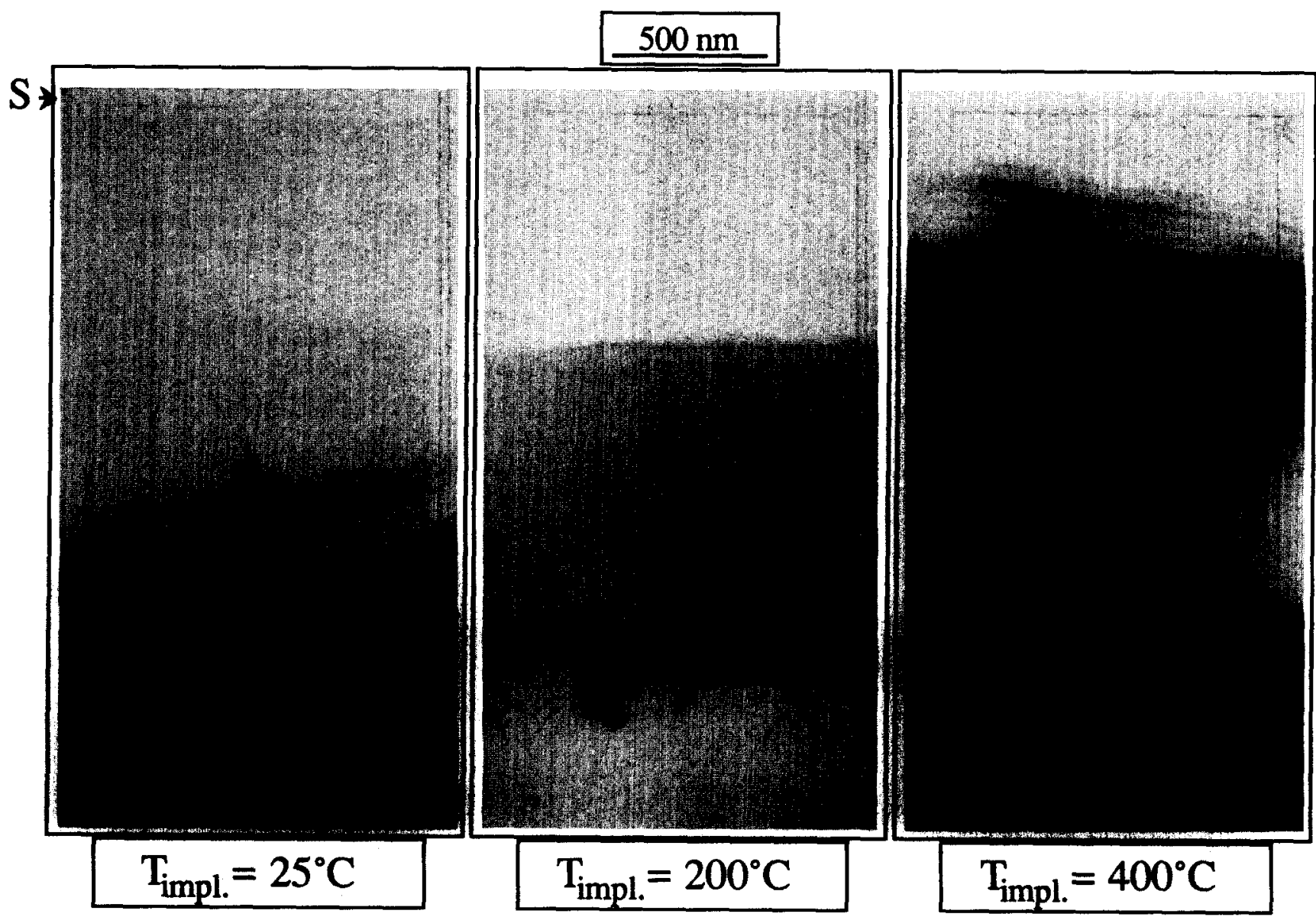

Fig. 3. XTEM images of silicon implanted with $5 \times 10^{14} \mathrm{~cm}^{-2} 1 \mathrm{MeV}$ boron at 25,200 , or $400^{\circ} \mathrm{C}$. Annealing was done at $900{ }^{\circ} \mathrm{C}$ for $15 \mathrm{~min}$. 
lower dechanneling is observed for the sample implanted at $400{ }^{\circ} \mathrm{C}$, where only $1.2 \times 10^{16} \mathrm{~cm}^{-2}$ displaced silicon atoms are detected. This is in agreement with earlier results for $40 \mathrm{keV}$ antimony implants, which

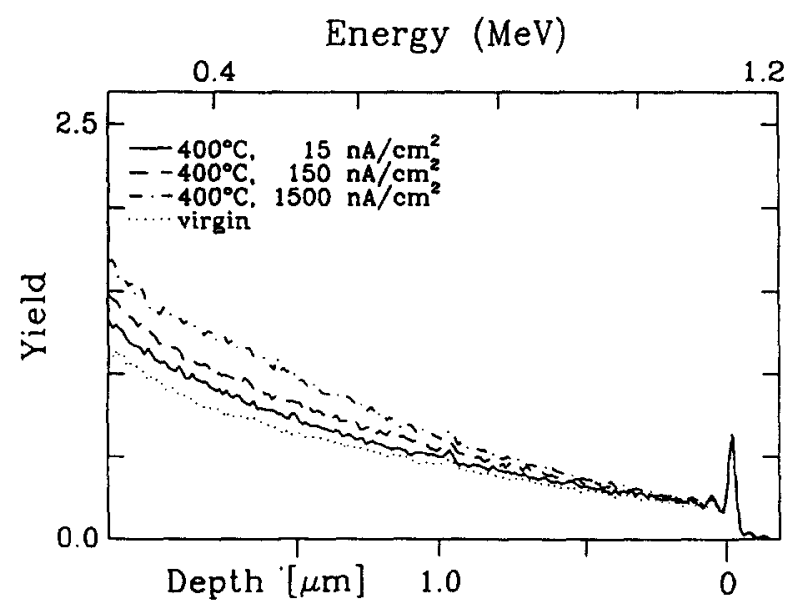

Fig. 4. RBS channeling spectra of silicon implanted with $5 \times 10^{14}$ $\mathrm{cm}^{-2} 1 \mathrm{MeV}$ boron at $400^{\circ} \mathrm{C}$ for current densities of 15,150 , or $1500 \mathrm{nA} \mathrm{cm}{ }^{-2}$. A channeling spectrum of unimplanted silicon is shown for comparison. also show a greater reduction in disorder for implants done at elevated temperature, as opposed to samples only annealed at higher temperatures [17].

XTEM images of these samples after $15 \mathrm{~min}, 900{ }^{\circ} \mathrm{C}$ anneals are shown in Fig. 10. A band with a high concentration of dislocation loops at a depth of $0.4 \mu \mathrm{m}$ is observed for both RT implanted samples. Thus, the pre-anneal at $400{ }^{\circ} \mathrm{C}$ for $3 \mathrm{~h}$ does not influence dislocation formation. However, XTEM analysis of the sample implanted at $400^{\circ} \mathrm{C}$ shows a much lower concentration of dislocation loops. Hence, only performing the $1 \mathrm{MeV}$ indium implant at elevated temperatures alters the dislocation formation. This implies that annealing of the a-zones during the implant reduces the point defect population, and thereby helps suppress dislocation formation.

\subsection{Combined boron and indium implants}

For the $1 \mathrm{MeV}$ indium implants, a dependence of the critical dose for dislocation formation on implant temperature was observed. This is in contrast with the results for the boron implants, where the only number relevant for dislocation formation was the total number

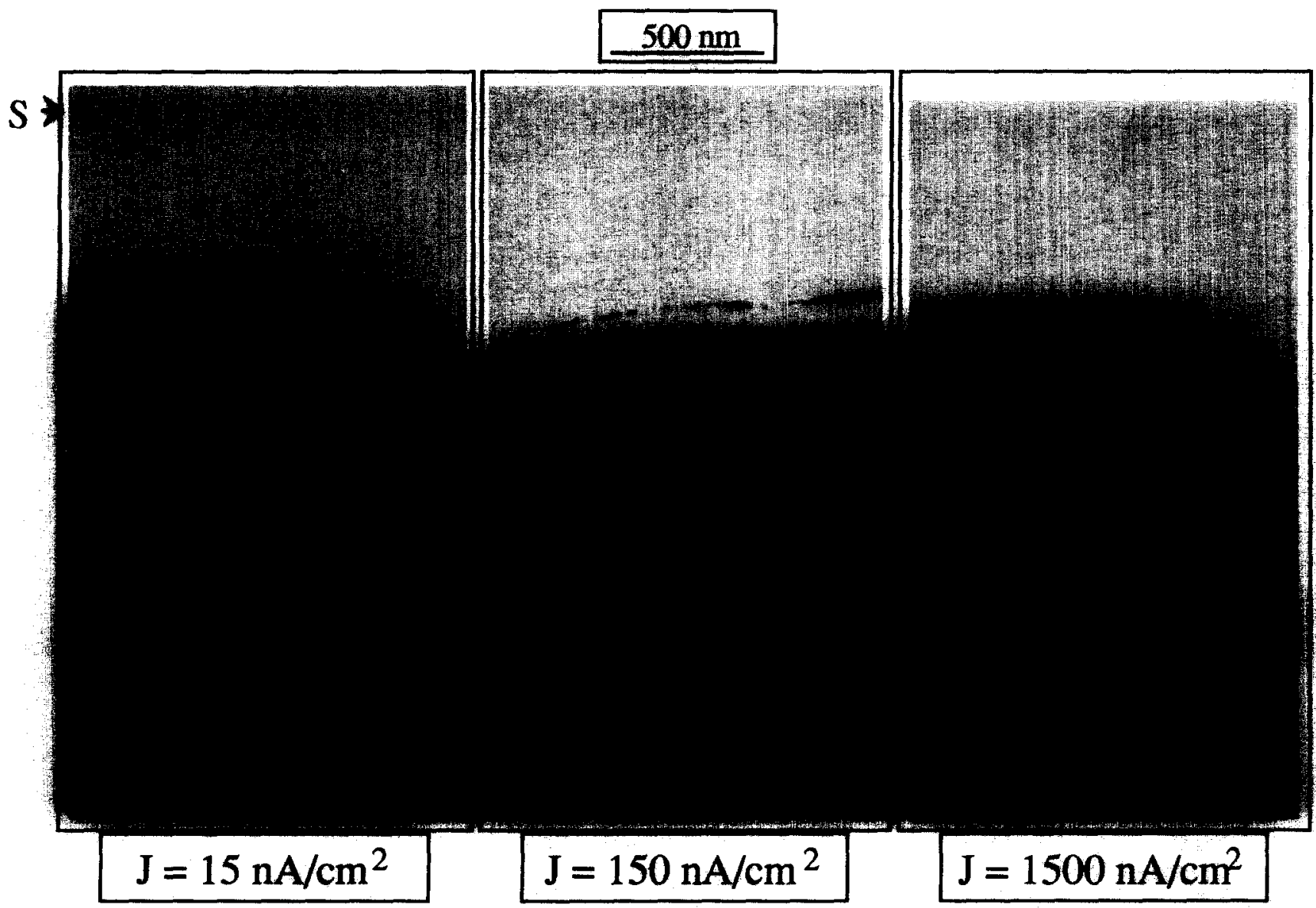

Fig. 5. XTEM images of $5 \times 10^{14} \mathrm{~cm}^{-2} 1 \mathrm{MeV}$ boron implanted at $400^{\circ} \mathrm{C}$ for current densities of 15,150 , or $1500 \mathrm{nA} \mathrm{cm}{ }^{-2}$. Annealing was carried out at $900^{\circ} \mathrm{C}$ for $15 \mathrm{~min}$. 

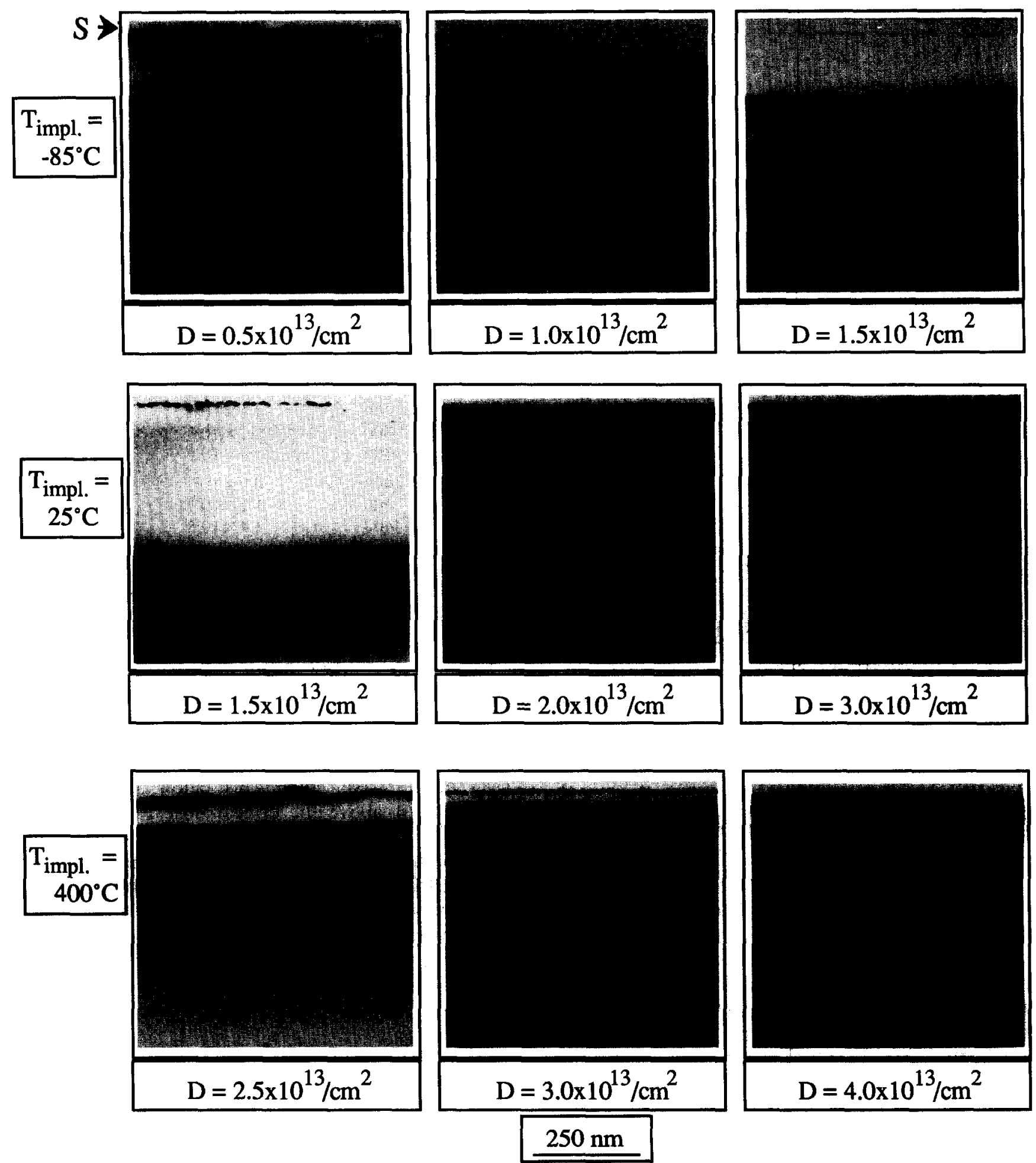

Fig. 6. XTEM images of silicon implanted with $1 \mathrm{MeV}$ indium at $-85,25$, or $400^{\circ} \mathrm{C}$ for different doses. Annealing was done at $900{ }^{\circ} \mathrm{C}$ for $15 \mathrm{~min}$. 


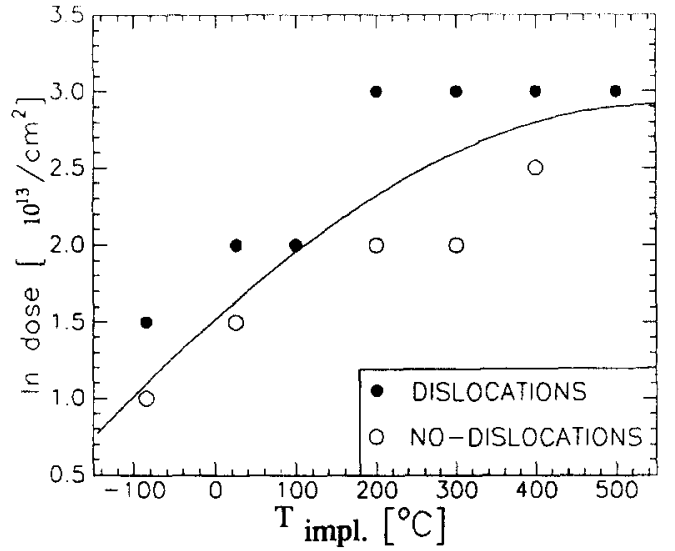

Fig. 7. Summary of XTEM results for $1 \mathrm{MeV}$ indium implants. The full drawn line gives the estimated critical dose for dislocation formation.

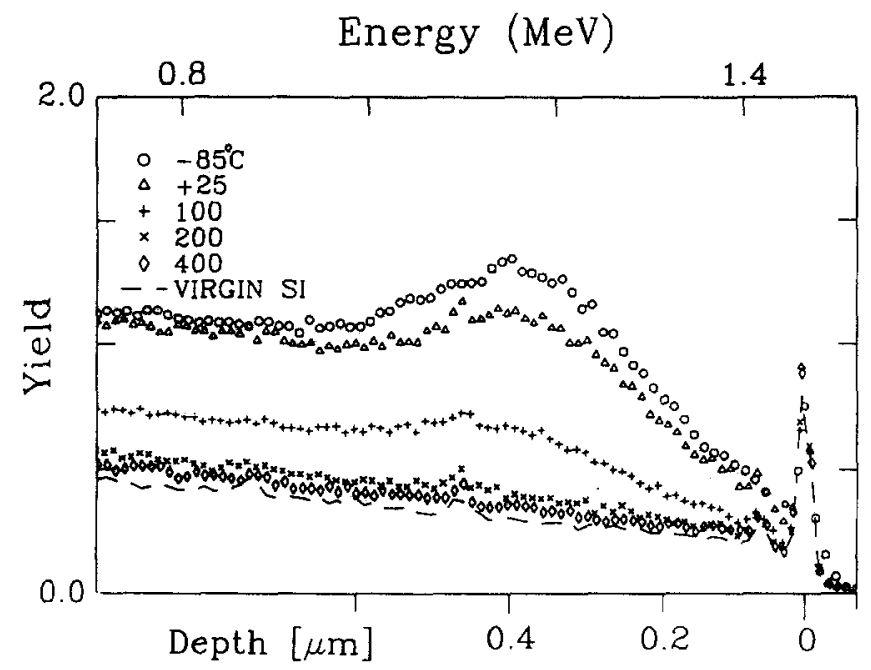

Fig. 8. RBS channeling spectra for indium doses closest to the critical dose for dislocation formation.

of silicon atoms displaced during the implant. The damage generated by indium implants differs from that induced by boron implants by the formation of a-zones, which apparently influences the point defect population and consequently dislocation formation. Sadana $e t$ al. suggested that a-c interfaces can act as traps for silicon interstitials, leaving a lower number of interstitials for forming dislocations [18]. By analogy, a-zones could also act as interstitial traps. To test this, combined boron and indium implants were carried out to see whether (regrowing) a-zones trap interstitials. Indium was implanted at $1 \mathrm{MeV}$ at $\mathrm{RT}$ to a dose of $0.75 \times 10^{13} \mathrm{~cm}^{-2}$, half the dose required for dislocation formation (Fig. 7). A significant fraction of the damage generated by this implant is in the form of a-zones. Next, $200 \mathrm{keV}$ boron was implanted to doses of either 0.7 to $1.0 \times 10^{14} \mathrm{~cm}^{-2}$. These boron implants should
TABLE 1. Overview of the implant doses and temperatures for the $1 \mathrm{MeV}$ indium implants, including the number of displaced silicon atoms estimated from RBS and information concerning dislocation formation (- no dislocations, + dislocations)

\begin{tabular}{|c|c|c|c|}
\hline $\begin{array}{l}\text { Indium dose } \\
\left(10^{13} \mathrm{~cm}^{-2}\right)\end{array}$ & $\begin{array}{l}\text { Implant } \\
\text { temperature }\left({ }^{\circ} \mathrm{C}\right)\end{array}$ & $\begin{array}{l}\text { Silicon atoms } \\
\text { displaced }\left(\mathrm{cm}^{-2}\right)\end{array}$ & Dislocations \\
\hline 0.5 & -85 & $6.0 \times 10^{16}$ & - \\
\hline 1.0 & -85 & $1.9 \times 10^{17}$ & $-1+$ \\
\hline 1.5 & -85 & $3.6 \times 10^{17}$ & + \\
\hline 1.5 & 25 & $1.5 \times 10^{17}$ & - \\
\hline 2.0 & 25 & $1.9 \times 10^{17}$ & + \\
\hline 3.0 & 25 & $3.6 \times 10^{17}$ & + \\
\hline 2.0 & 100 & $5.0 \times 10^{16}$ & $-1+$ \\
\hline 3.0 & 100 & $8.1 \times 10^{16}$ & + \\
\hline 4.0 & 100 & $9.5 \times 10^{16}$ & + \\
\hline 2.0 & 200 & $2.4 \times 10^{16}$ & - \\
\hline 3.0 & 200 & $3.4 \times 10^{16}$ & + \\
\hline 4.0 & 200 & $3.5 \times 10^{16}$ & + \\
\hline 2.0 & 300 & $1.1 \times 10^{16}$ & - \\
\hline 3.0 & 300 & $1.1 \times 10^{16}$ & + \\
\hline 4.0 & 300 & $1.4 \times 10^{16}$ & + \\
\hline 2.5 & 400 & $0.9 \times 10^{16}$ & - \\
\hline 3.0 & 400 & $1.2 \times 10^{16}$ & + \\
\hline 4.0 & 400 & $1.4 \times 10^{16}$ & + \\
\hline 3.0 & 500 & $0.5 \times 10^{16}$ & - \\
\hline 4.0 & 500 & $0.4 \times 10^{16}$ & + \\
\hline 6.0 & 500 & $0.8 \times 10^{16}$ & + \\
\hline 3.0 & 25 & $3.6 \times 10^{17}$ & + \\
\hline 3.0 & 25 and $400,3 \mathrm{~h}$ & $4.7 \times 10^{16}$ & + \\
\hline 3.0 & 400 & $1.2 \times 10^{16}$ & + \\
\hline
\end{tabular}

only add simple point defects. (From Fig. 1, it can be seen that $0.7 \times 10^{14} \mathrm{~cm}^{-2}$ is just below; and $1.0 \times 10^{14}$ $\mathrm{cm}^{-2}$ is just above the critical dose for dislocation formation for single implants.) If the a-zones generated by the indium implant trapped a significant number of the interstitials created by the boron implant, then dislocations would not form for either implant. Parts of these samples first received an anneal at $400{ }^{\circ} \mathrm{C}$ for $3 \mathrm{~h}$. The largest a-zones will not regrow during this anneal [4], while the interstitials will be highly mobile. Hence, interstitials should be able to diffuse and interact with the a-zones.

XTEM images of the samples after the final $900^{\circ} \mathrm{C}$ anneal for $15 \mathrm{~min}$ are presented in Fig. 11. Dislocations are observed not only for the sample which was implanted with $1.0 \times 10^{14} \mathrm{~B} \mathrm{~cm}^{-2}$, but also for the sample with the sub-critical boron dose of $0.7 \times 10^{14} \mathrm{~B}$ $\mathrm{cm}^{-2}$. The number of defects found is highest for the boron dose of $1.0 \times 10^{14} \mathrm{~B} \mathrm{~cm}^{-2}$. If a pre-anneal at $400{ }^{\circ} \mathrm{C}$ is carried out, the same density of dislocations is observed. Therefore, even if a-zones are in the vicinity of highly mobile interstitials, they have no influence 


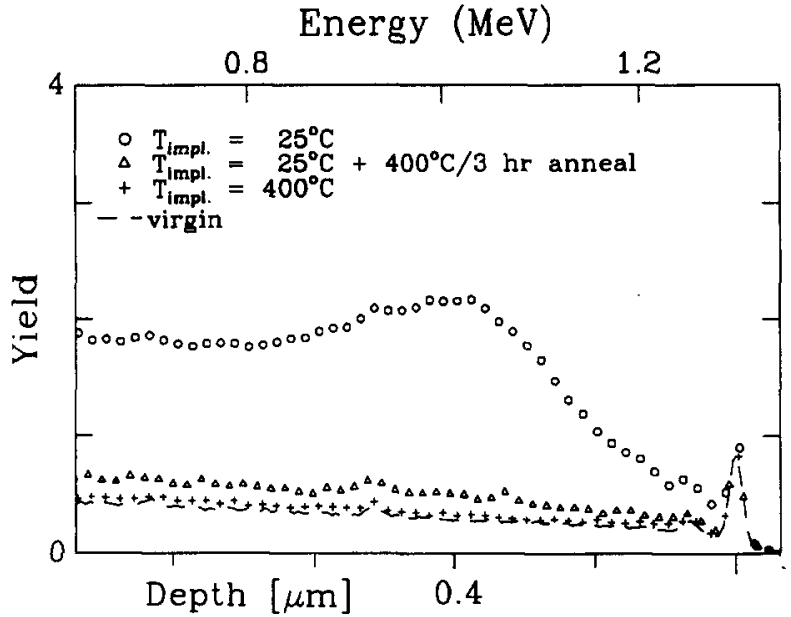

Fig. 9. RBS channeling spectra of silicon implanted with $3 \times 10^{13}$ $\mathrm{cm}^{-2} 1 \mathrm{MeV}$ indium at RT or $400^{\circ} \mathrm{C}$. Part of the RT implanted sample received an anneal at $400^{\circ} \mathrm{C}$ for $3 \mathrm{~h}$.

on dislocation formation. From these results it is concluded that a-zones are not efficient traps for interstitials created by its own, or another implant.

Implanting indium at elevated temperatures affects the formation of amorphous silicon and therefore has a strong influence on damage formation. In the complicated build-up and dynamic annealing of primary damage for high mass implants, the point defect population can also be altered, which consequently influences dislocation formation. For elevated temperature implants of boron, the interaction of damage is less complicated and dislocation formation is not influenced by increasing the implant temperature.

\section{Pre-amorphization damage vs. EOR-loop formation}

For RT implants of $150 \mathrm{keV}$ indium, amorphization takes place before the critical number of silicon atoms needed for dislocation formation is displaced, and endof-range dislocation loops (EOR-loops) are observed after annealing $[5,6]$. However, if these implants are carried out at an elevated temperature, amorphization should be suppressed and pre-amorphization damage may result instead.

Figure 12 shows RBS channeling spectra of $150 \mathrm{keV}$ indium implants done at 25 and $300^{\circ} \mathrm{C}$ for doses of $3 \times 10^{14}, 6 \times 10^{13}$, and $3 \times 10^{13} \mathrm{~cm}^{-2}$. The implant of $3 \times 10^{14} \mathrm{In} \mathrm{cm}^{-2}$ at RT creates a $110 \mathrm{~nm}$ thick amorphous surface layer. If the indium dose is lowered to $6 \times 10^{13} \mathrm{~cm}^{-2}$, only a buried amorphous layer is formed. In the case of the lowest dose, $3 \times 10^{13} \mathrm{~cm}^{2}$, the dechanneling yield does not reach the random level, indicating that a highly damaged silicon region
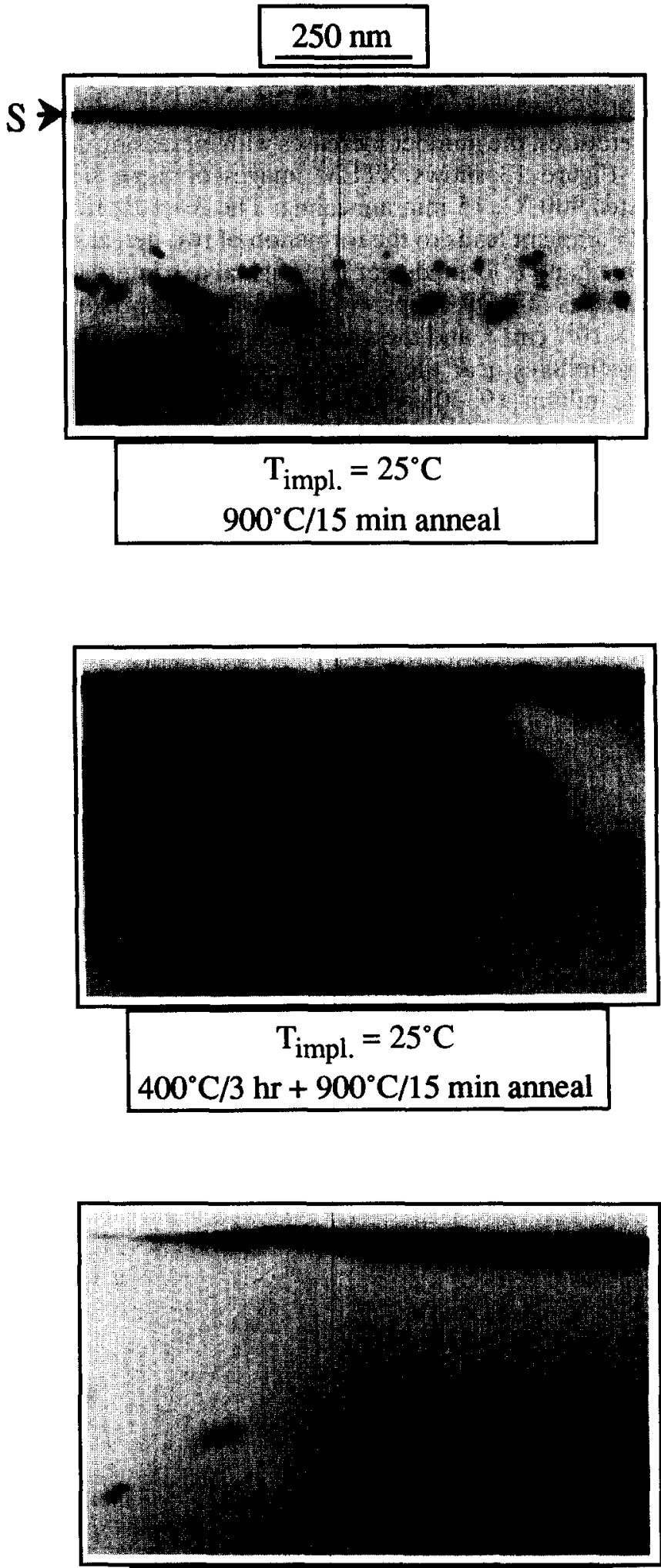

$$
\begin{gathered}
\mathrm{T}_{\mathrm{impl} .}=400^{\circ} \mathrm{C} \\
900^{\circ} \mathrm{C} / 15 \mathrm{~min} \text { anneal }
\end{gathered}
$$

Fig. 10. XTEM images of silicon implanted with $3 \times 10^{13} \mathrm{~cm}^{-2} 1$ $\mathrm{MeV}$ indium after final annealing at $900^{\circ} \mathrm{C}$ for $15 \mathrm{~min}$. Implant and anneal temperatures are denoted in the figure. 
has formed. In contrast, for the $300{ }^{\circ} \mathrm{C}$ implants, only small direct scattering peaks are observed by RBS. The numbers of displaced silicon atoms for the 25 and $300{ }^{\circ} \mathrm{C}$ implants are given in Table 2 . For both temperatures, the number increases with increasing dose.

Figure 13 shows XTEM images of these samples after $900{ }^{\circ} \mathrm{C}, 15 \mathrm{~min}$ annealing. The $3 \times 10^{14} \mathrm{In} \mathrm{cm}^{-2}$ RT implant leads to the formation of two defect bands. One band is located near the original a-c interface and consists of EOR-loops with a density of approximately $2 \times 10^{10} \mathrm{~cm}^{-2}$, and the second consists of small indium precipitates near the projected range $\left(R_{\mathrm{p}}=40 \mathrm{~nm}\right)$ of the indium $[19,20]$. XTEM of the as-implanted sample for an indium dose of $6 \times 10^{13} \mathrm{~cm}^{-2}$ shows the forma- tion of a $30 \mathrm{~nm}$ thick buried amorphous layer. Heavily damaged crystalline silicon is observed above and below this amorphous layer, resulting in dislocation formation during the anneal at $900{ }^{\circ} \mathrm{C}$. XTEM of the sample after the $3 \times 10^{13} \mathrm{In} \mathrm{cm}^{-2} \mathrm{RT}$ implant shows a damaged crystalline region, in agreement with the RBS measurement. Annealing of this structure also results in dislocation formation. XTEM after annealing of the sample implanted at $300{ }^{\circ} \mathrm{C}$ with $3 \times 10^{14} \mathrm{In} \mathrm{cm}^{-2}$ shows the formation of a dislocation network near $R_{\mathrm{p}}$, along with several small precipitates (Fig. 13). These dislocations are identified as pre-amorphization damage and are much larger and more complicated than the EOR-loops observed for the RT implant.
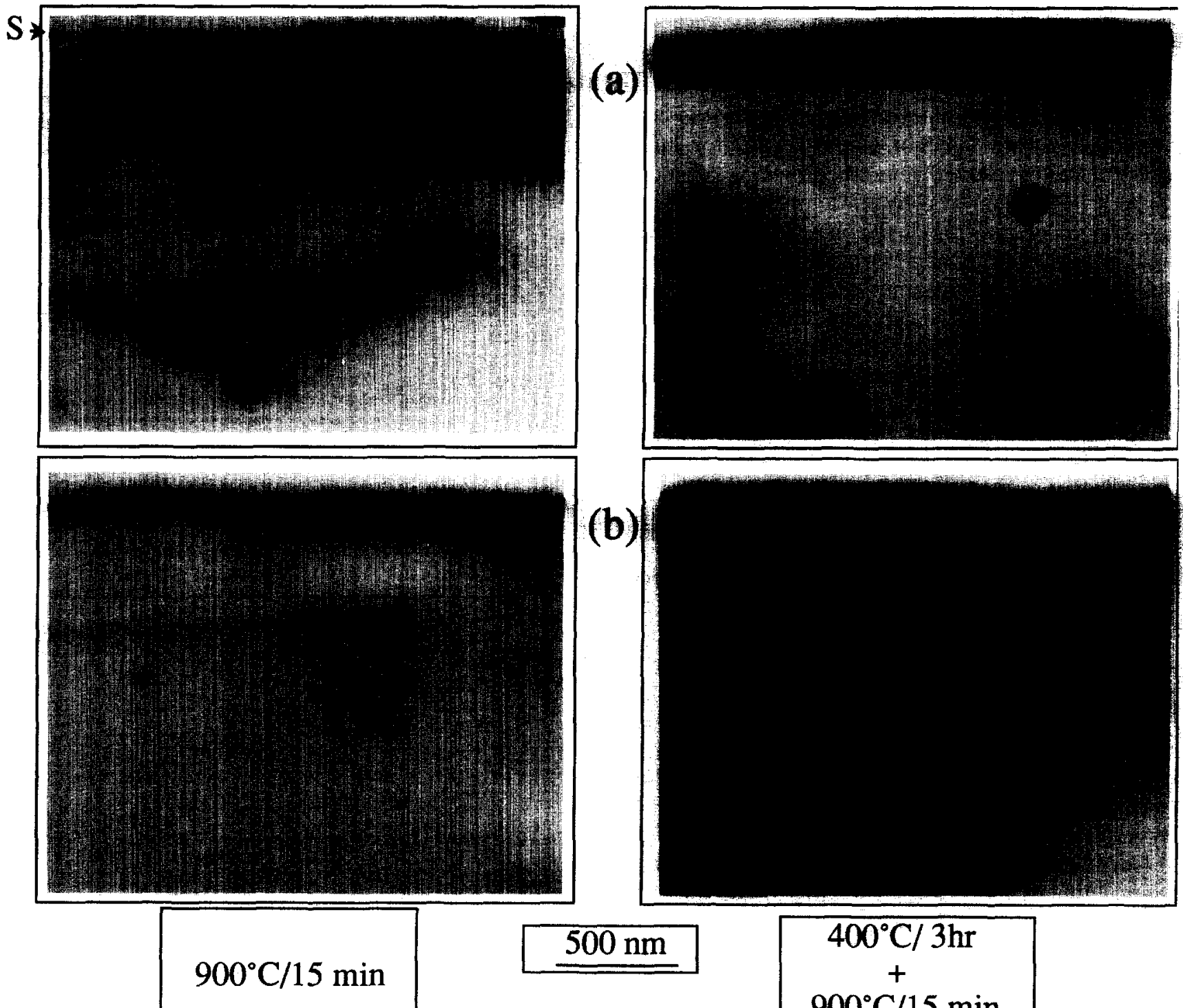

$500 \mathrm{~nm}$

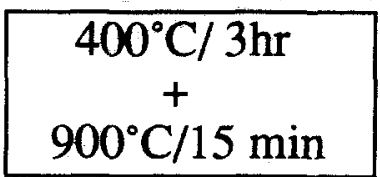

Fig. 11. XTEM images after $900^{\circ} \mathrm{C}, 15 \mathrm{~min}$ annealing of samples implanted with $0.75 \times 10^{13} \mathrm{~cm}^{-2} 1 \mathrm{MeV}$ indium and $200 \mathrm{keV}$ boron to doses of (a) $0.7 \times 10^{14} \mathrm{~cm}^{-2}$ or (b) $1.0 \times 10^{14} \mathrm{~cm}^{-2}$. Part of the samples first received an anneal at $400^{\circ} \mathrm{C}$ for $3 \mathrm{~h}$. 


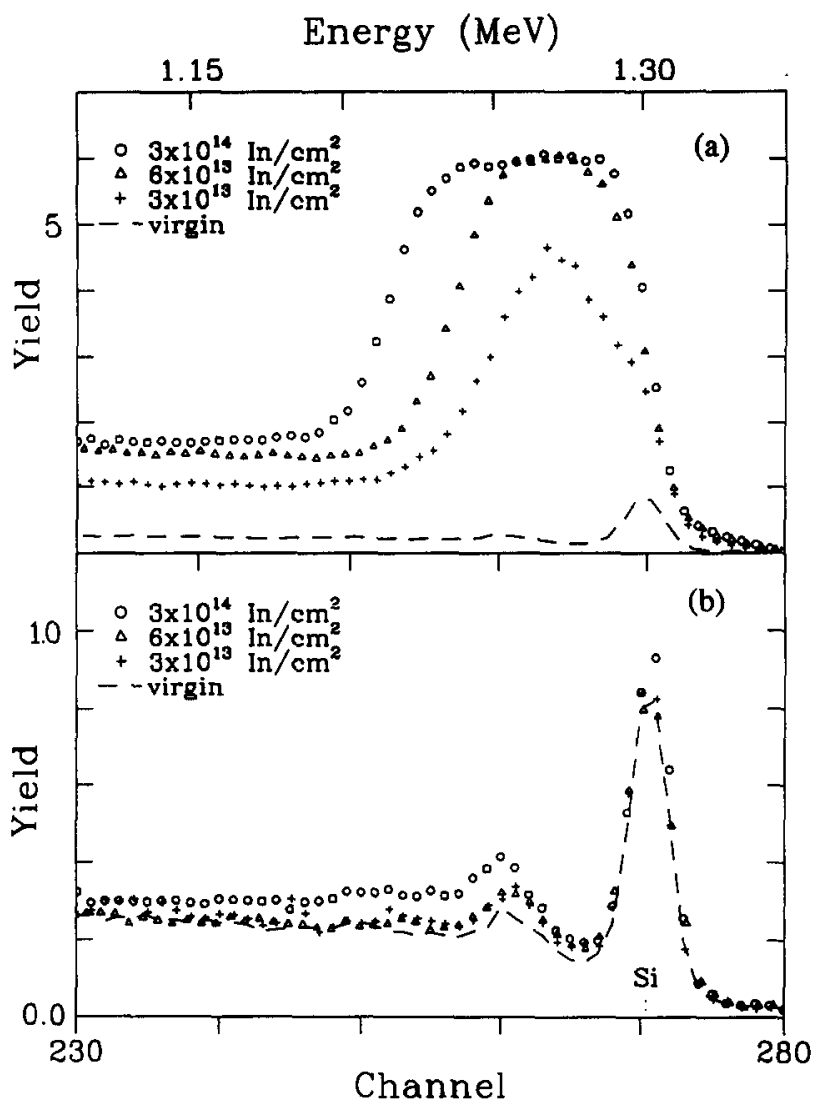

Fig. 12. RBS channeling spectra before annealing for $150 \mathrm{keV}$ indium implants done at RT or $300^{\circ} \mathrm{C}$. Doses and implant temperatures are indicated in the figure.

TABLE 2. Overview of the implant doses and temperatures for the $150 \mathrm{MeV}$ indium implants, including the number of displaced silicon atoms estimated from RBS and information concerning dislocation formation ( - no dislocations, + dislocations)

\begin{tabular}{llll}
\hline $\begin{array}{l}\text { Indium dose } \\
\left(10^{13} \mathrm{~cm}^{-2}\right)\end{array}$ & $\begin{array}{l}\text { Implant } \\
\text { temperature }\left({ }^{\circ} \mathrm{C}\right)\end{array}$ & $\begin{array}{l}\text { Silicon atoms } \\
\text { displaced }\left(\mathrm{cm}^{-2}\right)\end{array}$ & Dislocations \\
\hline 3 & 25 & $2.8 \times 10^{17}$ & + \\
6 & 25 & $4.6 \times 10^{17}$ & + \\
30 & 25 & $6.2 \times 10^{17}$ & + \\
3 & 300 & $3.2 \times 10^{15}$ & - \\
6 & 300 & $3.5 \times 10^{15}$ & + \\
30 & 300 & $9.9 \times 10^{15}$ & + \\
\hline
\end{tabular}

Thus, suppressing amorphization by implanting at higher temperatures can indeed result in the formation of pre-amorphization damage. The micrograph of the as-implanted structure for the indium dose of $6 \times 10^{13}$ $\mathrm{cm}^{-2}$ shows the presence of crystal damage, which again gives rise to dislocation formation during the furnace anneal. If the indium dose is lowered to $3 \times 10^{13} \mathrm{~cm}^{-2}$, crystal damage is still observed. How- ever, no dislocations remain after the anneal of this sample, which is in contrast with the RT implant. The amount of crystal damage for the $300{ }^{\circ} \mathrm{C}$ implant must have decreased to such a value that stable dislocations could not form during annealing.

A reduction in dislocation formation was observed for the $1 \mathrm{MeV}$ indium implants at elevated temperature (Section 3.2). In this section, it was shown that elevated temperature implants of $150 \mathrm{keV}$ indium for moderate doses can also reduce or suppress dislocation formation. However, for higher doses, increasing the implant temperature changes the secondary damage from the simple EOR-loops to a complicated dislocation network.

\section{EOR-loop formation for germanium implanted at RT and $L N_{2}$}

Pre-amorphization damage is avoided if the amount of crystal damage generated by the implant is below a critical value. Annealing an amorphous layer results in the formation of EOR-loops from agglomeration of silicon interstitials which are positioned in the a-c transition region. If the amount of crystal damage in the transition region is also reduced below a critical value by performing implants at low temperature, EOR-loop formation may be avoided. To investigate this, amorphizing implants of germanium were performed at RT and $\mathrm{LN}_{2}$.

Figure 14 presents RBS measurements of samples implanted with $75 \mathrm{keV}{ }^{73} \mathrm{Ge}$ for different doses and implant temperatures. A surface amorphous layer with a thickness of $100 \mathrm{~nm}$ is obtained for a $5 \times 10^{14} \mathrm{~cm}^{-2}$ RT implant. For a lower dose $\left(4 \times 10^{14} \mathrm{~cm}^{-2}\right)$ implant at $\mathrm{LN}_{2}$, the amorphous layer is almost as thick $(90 \mathrm{~nm})$. The germanium implanted structures were annealed at $400{ }^{\circ} \mathrm{C}$ for $1 \mathrm{~h}$ to avoid the formation of hairpin dislocations [6], at $600{ }^{\circ} \mathrm{C}$ for $1 \mathrm{~h}$ to induce regrowth of the amorphous layer, and at $900{ }^{\circ} \mathrm{C}$ for $15 \mathrm{~min}$ to anneal any remaining crystalline damage.

Cross-section and plan-view TEM images of the annealed samples are presented in Fig. 15. A band of EOR-loops at a depth of $100 \mathrm{~nm}$ is observed for the RT implant. The diameter of these loops is approximately $25 \mathrm{~nm}$ and their concentration is about $1 \times 10^{10}$ $\mathrm{cm}^{-2}$. In sharp contrast, no dislocations are observed for the $\mathrm{LN}_{2}$ implant. This means that the concentration of dislocations is lower than $1 \times 10^{5} \mathrm{~cm}^{-2}$, the detection limit for dislocations in plan-view TEM in our microscope.

The $\mathbf{L N}_{2}$ implanted sample was also directly annealed at $900^{\circ} \mathrm{C}$ for $15 \mathrm{~min}$. This anneal was, as for each anneal described in this paper, performed in a vacuum furnace where it takes some time for the sample to reach the final temperature. Hence, the 

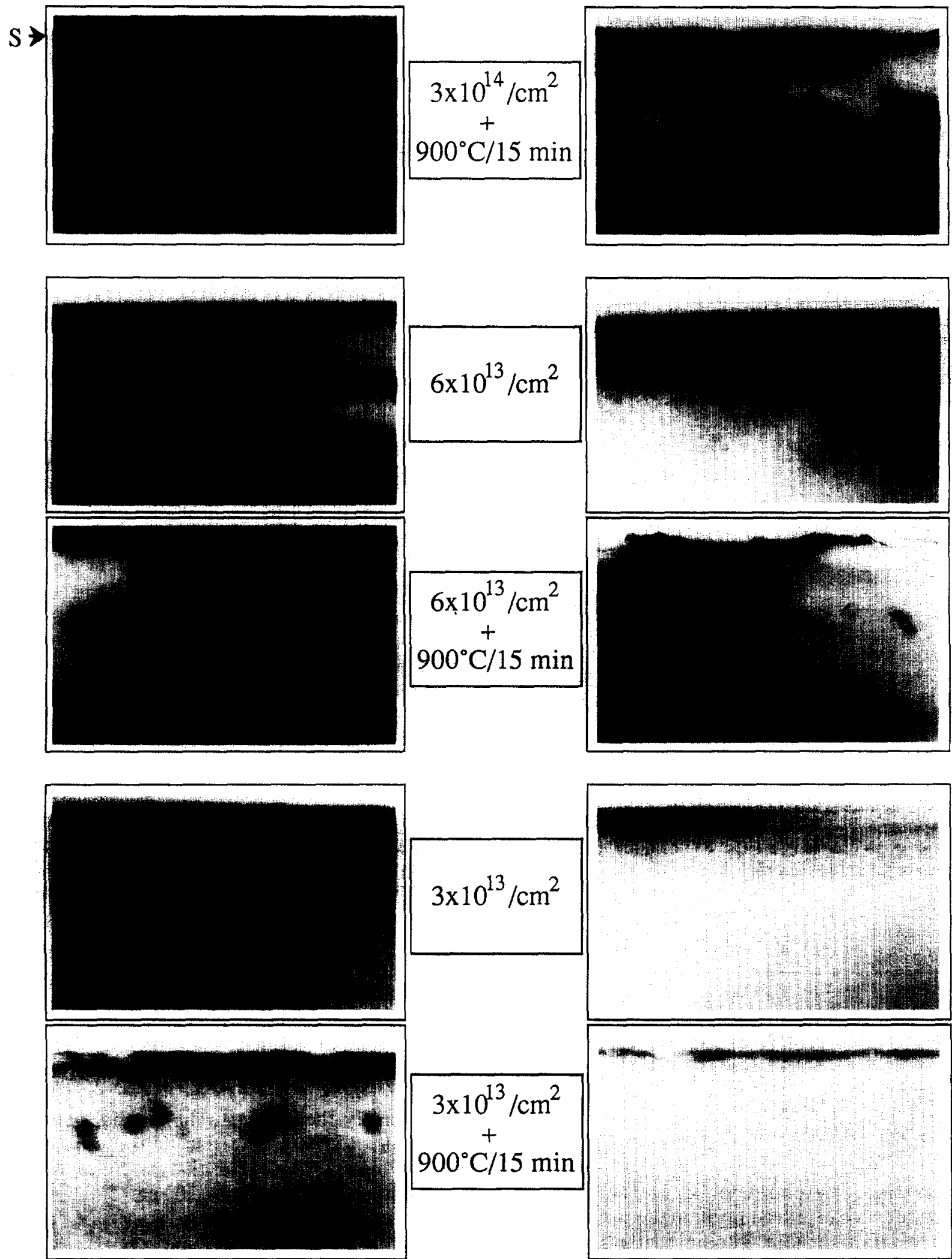

$\mathrm{T}_{\mathrm{impl} .}=25^{\circ} \mathrm{C}$

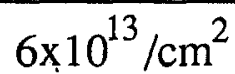

$+$ $900^{\circ} \mathrm{C} / 15 \mathrm{~min}$
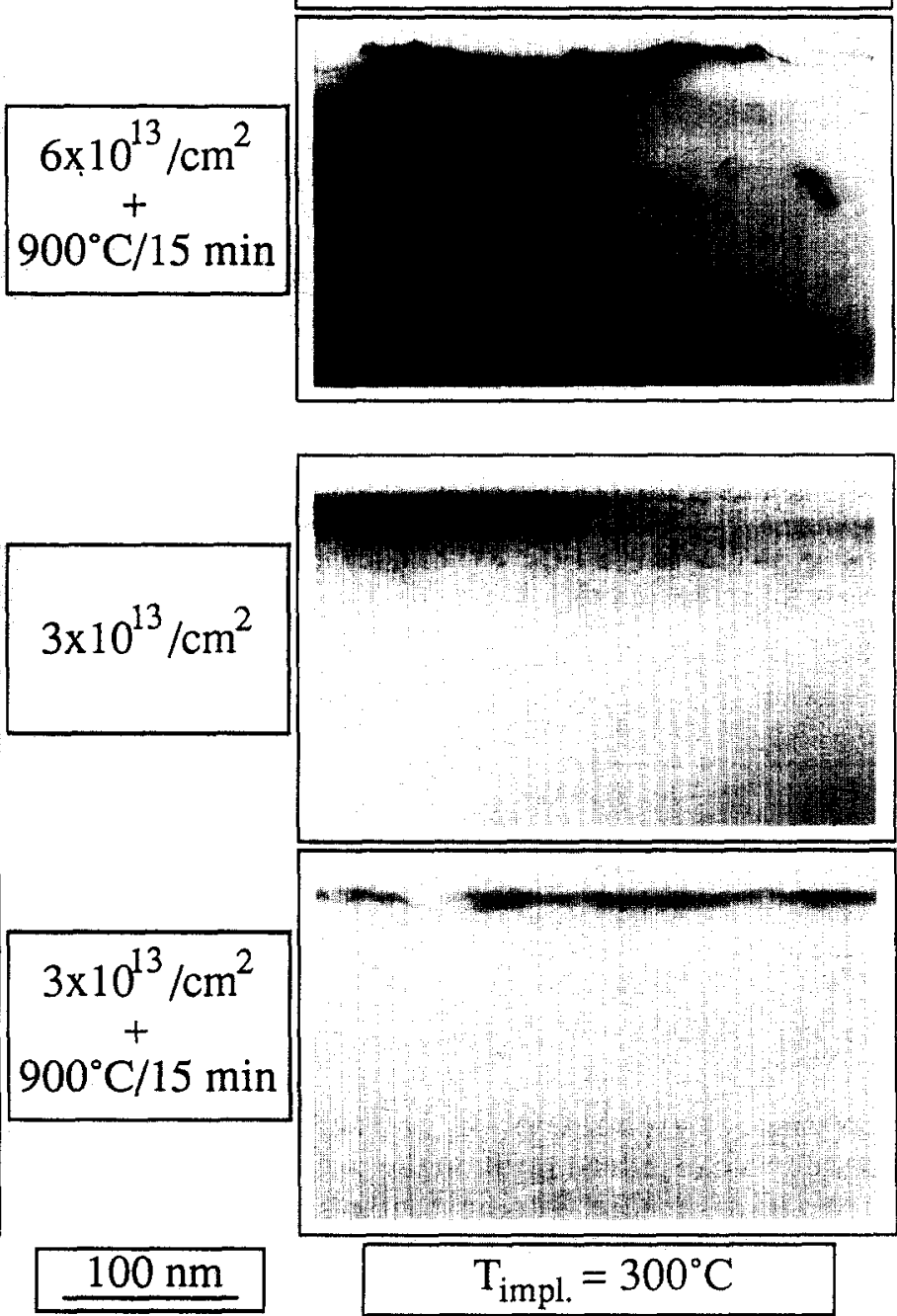

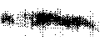

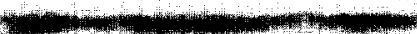

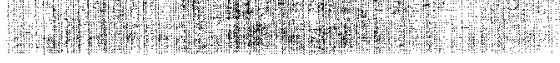

$\mathrm{T}_{\text {impl. }}=300^{\circ} \mathrm{C}$

Fig. 13. XTEM images of silicon implanted with $15 \mathrm{keV}$ indium at 25 or $300^{\circ} \mathrm{C}$ before and after $900{ }^{\circ} \mathrm{C}, 15 \mathrm{~min}$ annealing. Doses are indicated in the figures. 
amorphous layer will have regrown before the end temperature of $900{ }^{\circ} \mathrm{C}$ is reached. TEM analysis again shows no dislocations, so performing the one-step anneal at $900^{\circ} \mathrm{C}$ was sufficient.

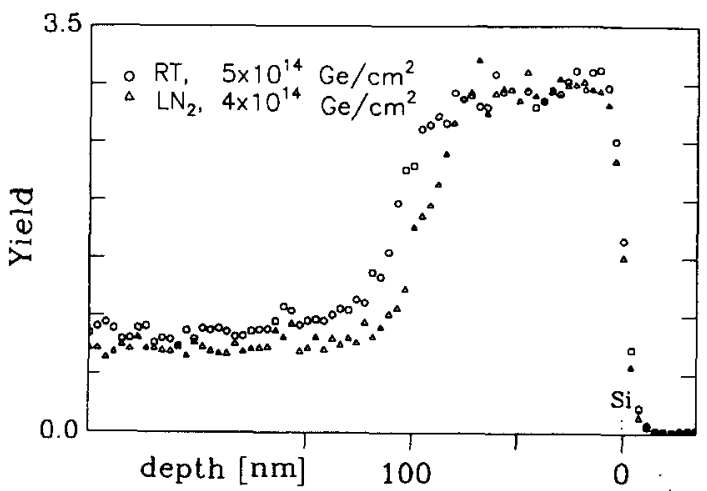

Fig. 14. RBS spectra before annealing of silicon implanted with $75 \mathrm{keV}$ germanium. The RT implanted sample received a dose of $5 \times 10^{14} \mathrm{~cm}^{-2}$ whereas the $\mathrm{LN}_{2}$ implanted sample received a dose of $4 \times 10^{14} \mathrm{~cm}^{-2}$.
Elimination of EOR-loops was observed for the germanium implanted samples if the implant was performed at $\mathrm{LN}_{2}$. It is known that silicon amorphizes more readily if the implant is performed at low temperatures and the amorphous layer will be thicker for the same implanted dose $[8,12]$. This thickness increase results in a lower amount of crystal damage beyond the $a-c$ interface $[12,13]$. The amount of crystal damage remaining after the $\mathrm{LN}_{2}$ implant must have been smaller than the amount needed for dislocation formation.

\section{Conclusions}

The formation of pre-amorphization damage was investigated for boron and indium implants. For boron implants, the only number which is significant for dislocation formation is the total number of silicon atoms displaced during the implant. The structure of defect complexes formed during implantation (the primary
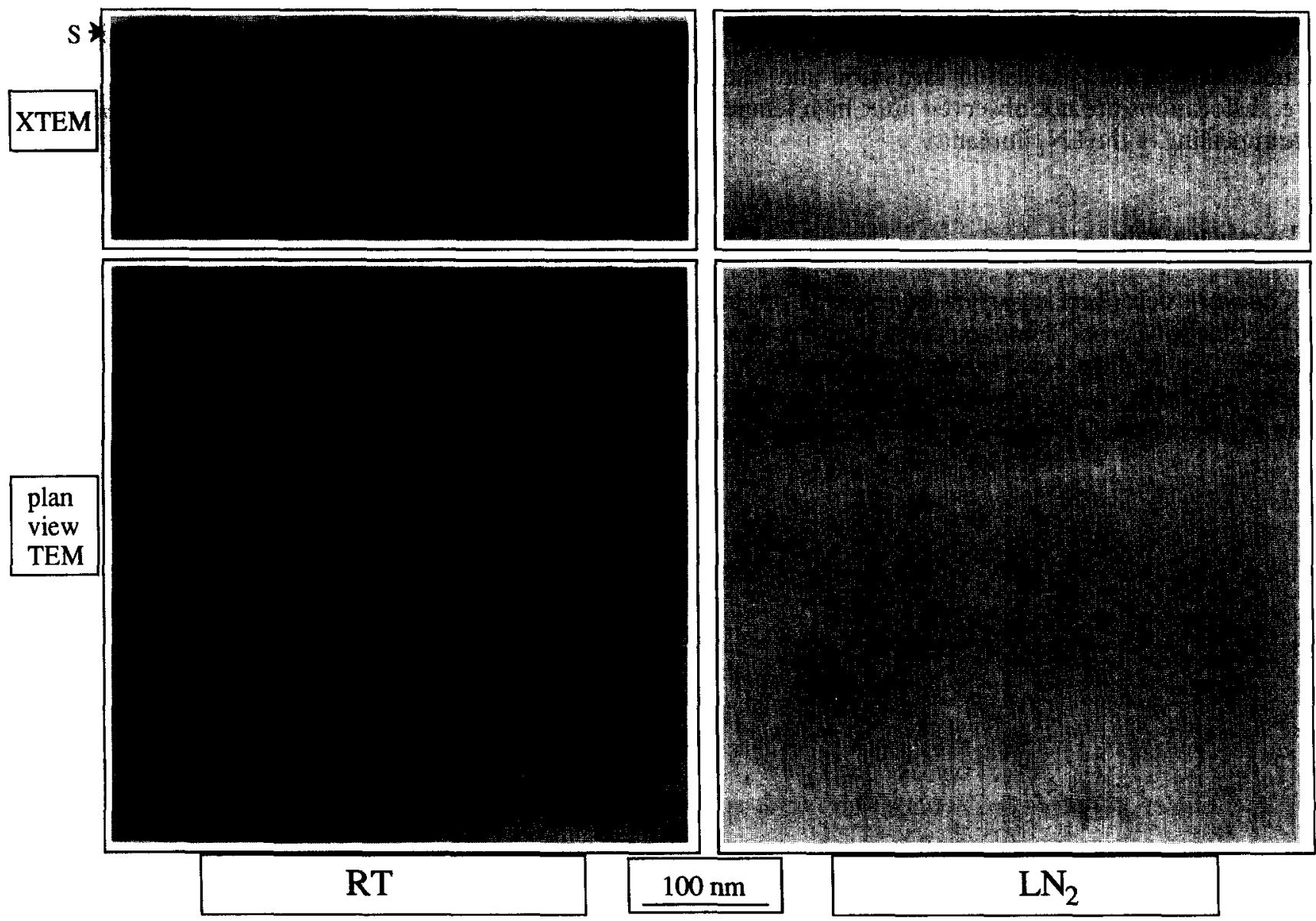

Fig. 15. XTEM and plan-view TEM images of silicon implanted with $75 \mathrm{keV}$ germanium after $900^{\circ} \mathrm{C}$ annealing for $15 \mathrm{~min}$. The RT implanted sample received a dose of $5 \times 10^{14} \mathrm{~cm}^{-2}$ and the $\mathrm{LN}_{2}$ implanted sample received a dose of $4 \times 10^{14} \mathrm{~cm}^{-2}$. 
damage), which is altered by changing the implant temperature or the current density, is not so critical. In the case of indium implants, where a-zones are a major part of the primary damage, the critical number of displaced silicon atoms needed for dislocation formation decreases by a factor of about 40 with increasing substrate temperature. For implants done above $300{ }^{\circ} \mathrm{C}$, the critical number is approximatley $10^{16} \mathrm{~cm}^{-2}$, close to the number found for boron implants for which no a-zones are created. The elevated temperature implants not only affect the formation of amorphous silicon but also the point defect population.

Implants of $150 \mathrm{keV}$ indium at $\mathrm{RT}$ result in complete amorphization before the critical amount of crystal damage is reached, so EOR-loops form after annealing. Increasing the implant temperature suppresses amorphization, and the formation of preamorphization damage is observed. If the implant dose is lowered, a sub-critical amount of crystal damage, less than $10^{16}$ displaced silicon atoms per square centimeter, is generated for the elevated temperature implant and dislocation formation is avoided.

Performing amorphizing germanium implants at $\mathrm{LN}_{2}$ instead of RT suppresses EOR-loop formation. The number of interstitials in the a-c transition region for the $\mathbf{L N}_{2}$ implant is probably lower than the critical number needed for dislocation formation and, therefore, dislocations are not observed after high temperature annealing of the $\mathrm{LN}_{2}$ implant.

\section{Acknowledgments}

The work described is part of the research program of the Stichting voor Fundamenteel Onderzoek der Materie (Foundation for Fundamental Research on Matter) and was made possible by financial support from the Nederlandse organisatie voor Wetenschappel- ijk Onderzoek (Netherlands Organization for Advancement of Research) and Varian Ion Implant Systems.

\section{References}

1 F. F. Morehead and B. L. Crowder, Radiat. Eff., 6(1970) 27.

2 H. J. Stein, F. L. Vook and J. A. Borders, Appl. Phys. Lett., 14 (1969) 328.

3 Y.-H. Lee, N. N. Gerasimenko and J. W. Corbett, Phys. Rev. $B, 14(1976) 4506$.

4 M. O. Ruault, J. Chaumont and H. Bernas, Nucl. Instrum. Methods, 209-210(1983) 351.

5 R. J. Schreutelkamp, J. S. Custer, J. R. Liefting, W. X. Lu and F. W. Saris, Mater. Sci. Rep., 6(1991) 275.

6 K. S. Jones, S. Prussin and E. R. Weber, Appl. Phys. A, 45 (1988) 1.

7 P. J. Schultz, C. Jagadish, M. C. Ridgway, R. G. Elliman and J. S. Williams, Phys. Rev. B, 14 (1991) 9118.

8 J. S. Williams, Mater. Res. Soc. Symp. Proc., 51 (1985) 83.

9 R. S. Nelson, European Conf. on Ion Implantation, Reading, 1970, Peregrinus, Bedford, 1971, p. 212.

10 K. S. Jones and D. Venables, J. Appl. Phys., 69(1991) 2931.

11 E. Ganin and A. Marwick, Mater. Res. Soc. Symp. Proc., 147 (1989) 13.

12 T. Suzuki, H. Yamaguchi, S. Ohzono and N. Natsuaki, Ext. Abstr. Int. Conf. on Solid State Devices and Materials, 1990 , Business Center Acad. Soc. Jpn., Tokyo, 1990, p. 1163.

13 K. Shoji, A. Fukami, T. Nagano, T. Tokuyama and C. Y. Yang, Appl. Phys. Lett., 60(1992) 451.

14 M. Servidori and I. Vecchi, Solid-State Electron., 24 (1981) 329.

15 W.-K. Chu, J. W. Mayer and M.-A. Nicolet, Backscattering Spectrometry, Academic Press, New York, 1978.

16 L. M. Howe and M. H. Rainville, Nucl. Instrum. Methods B, 19-20(1987) 61

17 S. T. Picraux, J. E. Westland, J. W. Mayer, R. R. Hart and O. J. Marsh, Appl. Phys. Lett., 14 (1969) 7.

18 D. K. Sadana, J. Washburn, P. F. Byrne and N. W. Cheung, Mater. Res. Soc. Symp. Proc., 14(1983) 511.

19 J. Narayan, O. W. Holland and B. R. Appleton, J. Vac. Sci. Technol. $B, 1(1983) 871$.

20 J. R. Liefting, J. S. Custer, R. J. Schreutelkamp and F. W. Saris, Proc. Int. School of Materials Science and Technology Conf., Erice, 1992, in press. 